Keywords: Anxiety; Biochemical markers; Biological psychiatry; Oxidative Stress; Phobic Anxiety.

\title{
Phobic anxiety and plasma levels of global oxidative stress in women
}

Kaitlin A. Hagan, MPH ${ }^{\star, \star \star}$

Tianying $\mathrm{Wu}, \mathrm{MD}, \mathrm{PhD}^{* * *}$

Eric B. Rimm, ScD $D^{\star, \star \star, \star \star \star \star}$

A. Heather Eliassen, $\mathrm{ScD}^{\star, * *}$

Olivia I. Okereke, MD, SM ${ }^{\star, \star \star, \star \star \star \star * \star}$

* Channing Division of Network Medicine, Department of Medicine, Brigham and Women's Hospital and Harvard Medical School, Boston, MA

** Department of Epidemiology, Harvard School of Public Health, Boston, MA

*** Division of Epidemiology and

Biostatistics, Department of Environmental Health, University of Cincinnati Medical Center, Cincinnati, $\mathrm{OH}$

**** Department of Nutrition, Harvard School of Public Health, Boston, MA

***** Division of Psychiatry, Brigham and Women's Hospital and Harvard Medical School, Boston, MA

USA

\footnotetext{
ABSTRACT - Background and Objectives: Psychological distress has been hypothesized to be associated with adverse biologic states such as higher oxidative stress and inflammation. Yet, little is known about associations between a common form of distress -phobic anxiety- and global oxidative stress. Thus, we related phobic anxiety to plasma fluorescent oxidation products (FlOPs), a global oxidative stress marker.

Methods: We conducted a cross-sectional analysis among 1,325 women (aged 43-70 years) from the Nurses' Health Study. Phobic anxiety was measured using the Crown-Crisp Index (CCI). Adjusted least-squares mean log-transformed FlOPs were calculated across phobic categories. Logistic regression models were used to calculate odds ratios (OR) comparing the highest CCI category ( $\geq 6$ points) vs. lower scores, across FlOPs quartiles.

Results: No association was found between phobic anxiety categories and mean FlOP levels in multivariable adjusted linear models. Similarly, in multivariable logistic regression models there were no associations between FlOPs quartiles and likelihood of being in the highest phobic category. Comparing women in the highest vs. lowest FlOPs quartiles: FlOP_360: OR = 0.68 (95\% CI: $0.40-1.15)$; FlOP_320: OR = 0.99 (95\% CI: $0.61-1.61)$; FlOP_400: OR $=0.92(95 \%$ CI: $0.52,1.63)$
} 
Conclusions: No cross-sectional association was found between phobic anxiety and a plasma measure of global oxidative stress in this sample of middle-aged and older women.

Received: 20 May 2014

Revised: 10 November 2014

Accepted: 23 December 2014

\section{Introduction}

Anxiety is one the most prevalent forms of psychological distress ${ }^{1}$. Phobic anxiety, in particular, is an important category within the broad dimension of psychological distress, due to its early age-at-onset and chronic and persistent nature ${ }^{1,2}$. Phobic anxiety has been found to be associated with cardiovascular disease $^{3,4}$, and sudden death ${ }^{4}$, and it has been hypothesized to have adverse biological consequences, such as higher oxidative stress and inflammation ${ }^{5-7}$. Potential associations of phobic anxiety with oxidative stress are particularly intriguing, as oxidative damage is hypothesized not only to be a biological consequence of chronic psychological distress but also to play an important role in the development of psychopathology, including anxiety ${ }^{8}$.

Prior evidence has indicated higher levels of oxidative stress across a range of psychological disorders. For example, in a study conducted by Kuloglu et al. $2002^{9}$, significantly higher levels of lipid peroxidation products were found among participants with schizophrenia or bipolar disorder compared with healthy controls. Similarly, higher levels of a calculated oxidative stress index (ratio of urine isoprostanes to serum vitamin $\mathrm{E}$ levels) were observed among 58 participants with high levels of perceived stress ${ }^{10}$. Additionally, higher levels of 8-hydrocydeoxyguanosine, a marker of oxidative DNA damage, were found among 90 women with clinical depression in comparison to age-matched controls ${ }^{11}$.
Although numerous reports have positioned oxidative stress as one of several potential downstream physiologic consequences of chronic adverse psychological states (i.e., along with inflammation ${ }^{12-14}$ or hypercortisolism ${ }^{15}$ ), other work has focused on the reverse association. Indeed, some investigators $^{5,6,9,16}$ have hypothesized an etiologic role of oxidative stress in the development of psychological distress symptoms and psychiatric disorders. For example, studies conducted in mice found that genes involved with antioxidative metabolism were highly related to anxiety-like phenotypes, pointing to a relation of oxidative stress in the etiology of anxiety ${ }^{17-19}$. Nevertheless, such work remains little explored in humans. Higher levels of oxidative stress (in particular, elevated lipid peroxidation products) have been associated with depression ${ }^{20}$, anxiety disorders ${ }^{5}$, and obsessive-compulsive disorders ${ }^{6,21}$ but not with post-traumatic stress disorder ${ }^{22}$ in cross-sectional studies. Additionally, results from one study indicated that anxious women had impairment of several immune functions, including reduced total antioxidant capacity ${ }^{23}$. Overall, gaps remain in understanding how levels of anxiety relate to measures of oxidative stress. Furthermore, there have been very few larger-sample studies conducted among well-characterized participants such that important confounders may be addressed.

Thus, the objective of this study was to examine the cross-sectional relations between phobic anxiety and fluorescent oxidation prod- 
ucts (FlOPs) in a large sample of mid-life and older adult women in the Nurses' Health Study. This study design has value in addressing psychological distress-oxidative stress associations for two key reasons: 1) phobic anxiety has particular relevance due to its chronic nature and, thus, a plausible potential role in accumulation of oxidative damage; 2) quantification of FlOPs is a validated plasma marker of global oxidative stress and, thus, a useful tool in this context, given the hypothesized wideranging downstream effects of chronic anxiety.

\section{Methods}

\section{Study Population}

The Nurses' Health Study (NHS) included 121,700 U.S., female registered nurses, aged 30 to 55 at the study's inception in 1976. Since then, participants have complete biennial mailed questionnaires updating information on numerous lifestyle factors and health outcomes; total follow-up exceeds $90 \%$. Details regarding the NHS and validation of various health exposures and endpoints have been previously published ${ }^{24,25}$. During the 1988-1990 questionnaire cycle, participants were asked to complete the Crown-Crisp Index (CCI) of phobic anxiety ${ }^{26,27}$. From 1989 to $1990,32,826$ NHS participants provided blood samples; details of the blood collection and archival methods have been previously described ${ }^{28,29}$. Plasma FlOPs were measured from archived blood samples previous collected in the NHS: details of blood collection are provided elsewhere $^{28}$. Briefly, blood samples were collected from NHS participants using tubes treated with liquid sodium heparin. The tubes were then placed on ice packs, stored in Styrofoam containers, returned to the laboratory by overnight courier, centrifuged, and di- vided into aliquots for storage in liquid-nitrogen freezers $\left(-130^{\circ} \mathrm{C}\right.$ or colder $)$. The majority of specimens arrived at our lab for processing within 24 hours of collection ${ }^{28}$. Blood samples were collected proximal to measurements of phobic anxiety (mean time interval between CCI and blood collection = 18.7 months, or 1.5 years; over $92 \%$ of participants had an interval of $<2$ years and the maximum interval was 2.75 years).

The protocols for the NHS, the NHS blood collection, and the current study were approved by the Institutional Review Board of Brigham and Women's Hospital, Boston, MA, USA. Blood donors gave written informed consent to having their samples used for research purposed. In addition, all data was analyzed anonymously.

To determine the final study sample, we considered participants from nested casecontrol studies of pre-diagnostic FlOPs and incident breast cancer ${ }^{30}$ and cardiovascular disease $(\mathrm{CVD})^{31}$, and from a study of cognitive function (total $n=2,179$ ). Although blood collections occurred among cases and controls prior to the disease of interest, we utilized the most conservative approach and minimized possible bias by including only controls and the random sample of cognitive study participants (total $n=1,368$ ). We excluded women with insufficient CCI data (i.e., missing $>2$ items $)^{32}(n=40)$ or missing FlOP values $(n=3)$. Thus, the sample for analysis included 1,325 women.

\section{Assessment of phobic anxiety: the Crown-Crisp index}

The CCI measures symptoms of phobic anxiety. It has been validated in psychiatric outpatient settings and found to discriminate patients with general anxiety and phobias from healthy controls or those with disorders 
consisting of other symptom dimensions (i.e., obsessive-compulsive or depressive $)^{26,27}$. The CCI primarily covers aspects of "fear" disorders, such as panic disorder and agoraphobia. It features 8 self-rated questions, and total scores range from 0 to 16 points (higher scores indicate higher phobic anxiety). As in prior work $^{32}$, for those missing data on 1 or 2 items, we based the CCI sum score on only the answered items, rather than imputing CCI scores using the mean, as this may be a slightly more conservative approach to missing responses on self-reported symptom measures. CCI scores were are not normally distributed and in keeping with prior work ${ }^{33,34}$ we categorized CCI scores into 5 groups: 0 or 1 point (reference group); 2 points; 3 points; 4 or 5 points and $\geq$ 6 point (highest phobic group). As previously described $^{32}$, the CCI has been found to be reliable in the NHS cohort: e.g., the Cronbach coefficient alpha for scores in 1988 was 0.62 ; item-total correlations $(0.26-0.43)$ were in the desirable range ${ }^{35}$; and when the CCI was asked again on the 2004 NHS questionnaire, the interclass correlation coefficient (ICC) for the pair of CCI scores in 1988 and 2004 was 0.61 - indicating that these measures can reliably represent long-term phobic anxiety levels. The consistency of the score also points to the validity of the $\mathrm{CCI}$ in measuring phobic anxiety, as phobic anxiety is expected to be generally stable over time ${ }^{1}$.

\section{Measurement of FLOPs}

Fluorescent oxidation products (FlOPs) result from the interaction of reactive oxygen intermediates and free radicals with macromolecules ${ }^{36}$. Our fluorescent method provides a non-specific, but sensitive, measure of oxidative products from lipids, protein, carbohydrate and DNA, and is considered a global measure of oxidation ${ }^{37,38}$.
Measurement of fluorescent oxidation products (FlOPs) were performed with procedures previously described ${ }^{37,38}$. Briefly, plasma was extracted with ethanol-ether and measurements were obtained using a spectrofluorometer. FlOPs reflect lipid oxidation products from reactions with protein, DNA, and carbohydrate and the fluorescence was determined as relative fluorescence units per millimeter of plasma. In a previous prospective study involving a parallel cohort of men, we found this global measure of oxidation was stable in plasma samples that had been previously collected and placed in storage for 10 years, and reproducibility of FlOPs is high - with ICCs in paired samples up to three years apart that ranged from $0.43-0.70$ for the three FlOPs ${ }^{30,31,38}$. Furthermore, the measure showed good validity: it was highly correlated with cigarette smoking and was a strong independent predictor of coronary heart disease $(\mathrm{CHD})^{37,38}$. We measured three different FlOPs: FlOP_360 (excitation 360 nm, emission $420 \mathrm{~nm}$ ), FlOP_320 (excitation $320 \mathrm{~nm}$, emission $420 \mathrm{~nm}$ ), FlOP_400 (excitation $400 \mathrm{~nm}$, emission $475 \mathrm{~nm}$ ). FlOP_360 represents the interaction between lipid oxidation productions and protein, DNA, and carbohydrates $^{39}$. FlOP_320 represents the interaction of lipid oxidative products, particularly lineolate, with DNA and metals ${ }^{40,41}$. FlOP_400 represents the interaction between malondialdehyde (MDA), proteins, and phospholipids $^{41,42}$. The mean coefficients of variation (CVs) for FlOPs across the different lab batches used for our study were adequate and ranged from 7.4-19.2\%; 8 out of 12 batches had mean CVs below $15 \%$. In addition, FlOPs were shown to have better stability in plasma over 24-36 hours compared to more specific biomarkers of oxidative stress such as MDA or $\mathrm{F}_{2}$-isoprostanes ${ }^{39}$. 


\section{Assessment of covariates}

In addition to age-at-blood collection (increasing age is well-known to be related to cumulative oxidative stress), we considered numerous variables potentially associated with phobic anxiety and FlOPs. Using the biennial questionnaire completed proximal (19881990) to blood collection and a supplemental questionnaire administered at blood collection, we obtained information on numerous health, social and lifestyle factors for inclusion in multi-variable models: age at blood draw (continuous, years), body mass index (BMI) (continuous, $\mathrm{kg} / \mathrm{m}^{2}$ ), physical activity (continuous, metabolic-equivalent (METs)/week), alcohol consumption (continuous, g/d), smoking status (never, past, current), education (RN, Bachelor's, Master's/Doctoral), antidepressant use (yes/no), hypertension (yes/no), high cholesterol (yes/no), and cardiovascular disease (yes/no).

\section{Statistical analyses}

The distributions of FlOPs varied across batch sets from each nested case-control studies and the cognitive study. Therefore, we adjusted FlOP levels for batch according to methods describe by Rosner et al. $2008^{43}$. Statistical outliers were identified using the generalized extreme studentized deviate many-outlier detection approach ${ }^{44}$.

To examine the relationship between phobic anxiety and FlOPs, we estimated adjusted least-squares means of the log-transformed FlOPs using generalized linear models. In additional analyses, logistic regression models were used to calculate odds ratios for the highest CCI score $(\geq 6)$ vs. lower scores $(0-5)$ across quartiles of the three different FlOPs. Although prior work ${ }^{32,34}$ indicates that a score of $\geq 6$ on the CCI may indicate a critical threshold of anxiety symptoms, there may be other important contrasts involving subthreshold levels of anxiety, which have been addressed in prior NHS investigations ${ }^{4,45}$. Thus, we also utilized polytomous logistic regression models to investigate the relations of continuous log transformed FlOPs to finer contrasts of phobic anxiety rather than just the dichotomized approach; in these models, persons scoring $0 / 1$ on the CCI served as the reference group for comparisons with those in all higher categories of phobic anxiety. For all analyses, we looked at both age-adjusted and multivariable-adjusted models. In multivariable analyses, we considered factors that had the largest potential to contribute to confounding and additional covariates identified in prior literature. All statistical analyses were performed using SAS version 9.2 (SAS Institute Inc, Cary, NC).

\section{Results}

Table 1 shows sample characteristics at blood draw, across quartiles of the three different FlOPs (FlOP_360, FlOP_320, FlOP_400). Women in the highest quartiles of FlOPs were more likely to be current smokers, have hypertension, and consume greater amounts of alcohol.

In age-adjusted linear models, higher phobic anxiety was not associated with FlOP_360, FlOP_320, or FlOP_400. Results from the global F-test demonstrated that none of the means were significantly different across categories of phobic anxiety score for any of the FlOPs. For example, the geometric mean of FlOP_360 among those with high phobic anxiety (CCI score $\geq 6$ ) was $220 \mathrm{FI} / \mathrm{mL}$ (relative fluorescent intensity units per milliliter of plasma) (95\% CI: 207 - $233 \mathrm{FI} / \mathrm{mL})$ compared to $228 \mathrm{FI} / \mathrm{mL}$ (95\%: 220 - $236 \mathrm{FI} / \mathrm{mL}$ ) among those with lowest phobic anxiety score 


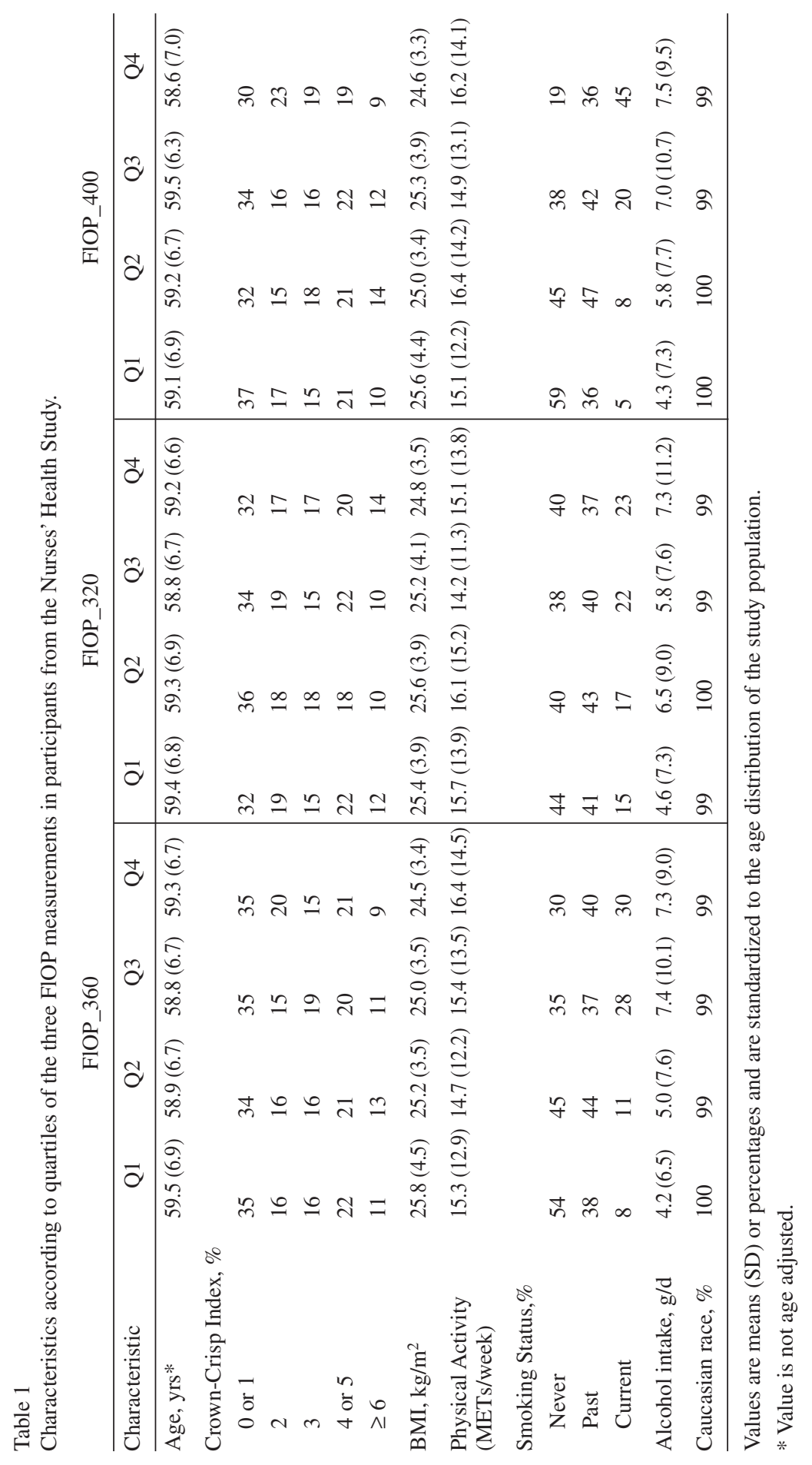




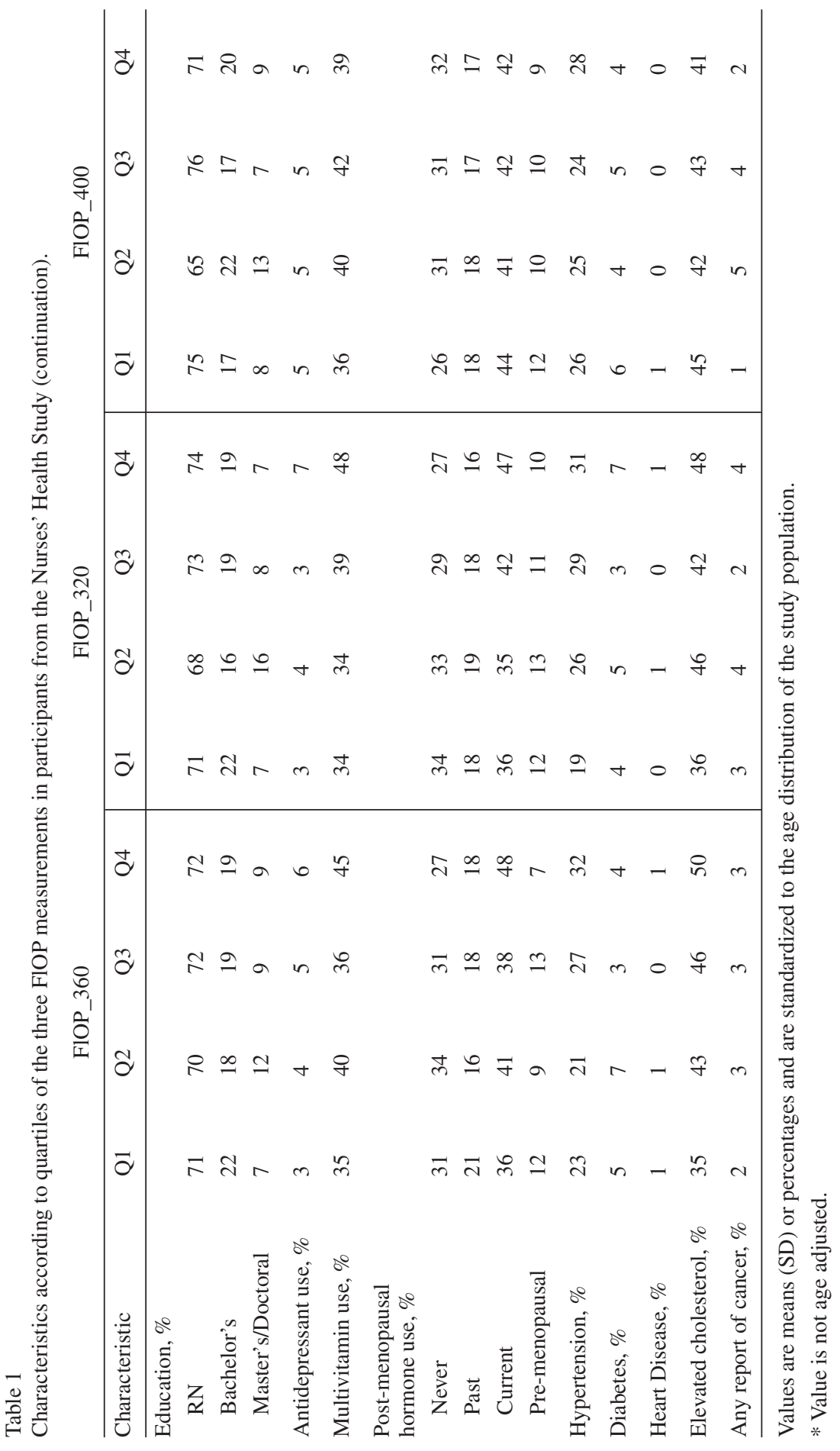


(CCI score of 0 or 1). Similarly, the geometric means of FlOP_320 and FlOP_400 among those with high phobic anxiety were 535 FI/mL (95\% CI: $455-629 \mathrm{FI} / \mathrm{mL})$ and 65 $\mathrm{FI} / \mathrm{mL}$ (95\% CI: $61-69 \mathrm{FI} / \mathrm{mL}$ ), compared to $533 \mathrm{FI} / \mathrm{mL}$ (95\% CI: $484-586 \mathrm{FI} / \mathrm{mL}$ ) and 63 FI/mL (95\% CI: 60 - 65 FI/mL) among those with lowest phobic anxiety score, respectively. Findings remained similar after adjusting for other covariates (Table 2).

In both age-adjusted and multivariable-adjusted logistic regression models there were no statistically significant associations between quartiles of any of the FlOPs with likelihood of having the highest level of phobic anxiety and all tests of trends were statistically non-significant (Table 3 ).

Comparing women in the highest vs. lowest FlOPs quartiles, the multivariable adjusted ORs for high phobic anxiety (Crown Crisp Score $\geq 6$ ) for FlOP_360 was 0.68 (95\% CI: $0.40-1.15$, p-trend $=0.2)$; 0.99 for FlOP_320 (95\% CI: $0.61-1.61$, p-trend $=0.8$ ); and 0.92 for FlOP_400 (95\% CI: 0.52, 1.63, p-trend = $0.6)$. Similarly, in both age-adjusted and multivariable-adjusted polytomous logistic models, there were no statistically significant associations found between the three different FlOPs and levels of phobic anxiety, including sub-threshold and minimal levels of anxiety (Supplementary Table 1).

\section{Discussion}

In this cross-sectional study of 1,325 women, we found no significant associations between phobic anxiety and plasma fluorescent oxidation products, a global measure of oxidative stress measured at three wavelengths. Furthermore, results did not change after adjustment for numerous potential confounders.
The null findings in the current study can be contrasted with previously reported evidence for links between psychological distress conditions, such as anxiety, and other oxidative stress markers. For example, several groups reported associations between MDA (a lipid peroxidation product) and specific psychiatric disorders, such as social phobia $^{16}$, panic disorder ${ }^{5}$ and major depressive disorder ${ }^{20,46}$. In addition, oxidative DNA damage has been observed among patients with major depressive disorder ${ }^{47}$ and bipolar disorder ${ }^{48}$. Furthermore, such evidence has not been limited to psychiatric clinical populations. For example, Irie et al. (2001, $2005)^{11,49}$, found indications of more oxidative DNA damage among persons with higher levels of occupational psychological stress and depression in more general participant samples. Nevertheless, the above mentioned studies reflect that existing evidence has primarily relied on data from clinical populations, had smaller sample sizes (n ranged from 90 to 362) and used specific markers of oxidative stress/injury. By contrast, in the current analysis we ascertained phobic anxiety -across a range from no to high levels of symptoms- in a large sample of over 1,300 community-dwelling participants and we utilized a global marker of oxidative stress.

The results in this report are also somewhat surprising in light of recent findings of a significant relation of high phobic anxiety to shorter relative leukocyte telomere lengths ${ }^{32}$. Thus, we might have expected an association between phobic anxiety and our plasma measure of oxidative stress, as telomere shortening is influenced by oxidative stress ${ }^{50}$. Furthermore, while it would have been useful to examine directly the correlation between telomere length and FlOPs within these same participants, there was not adequate overlap in these two samples in order to undertake this. Finally, an important potential explana- 


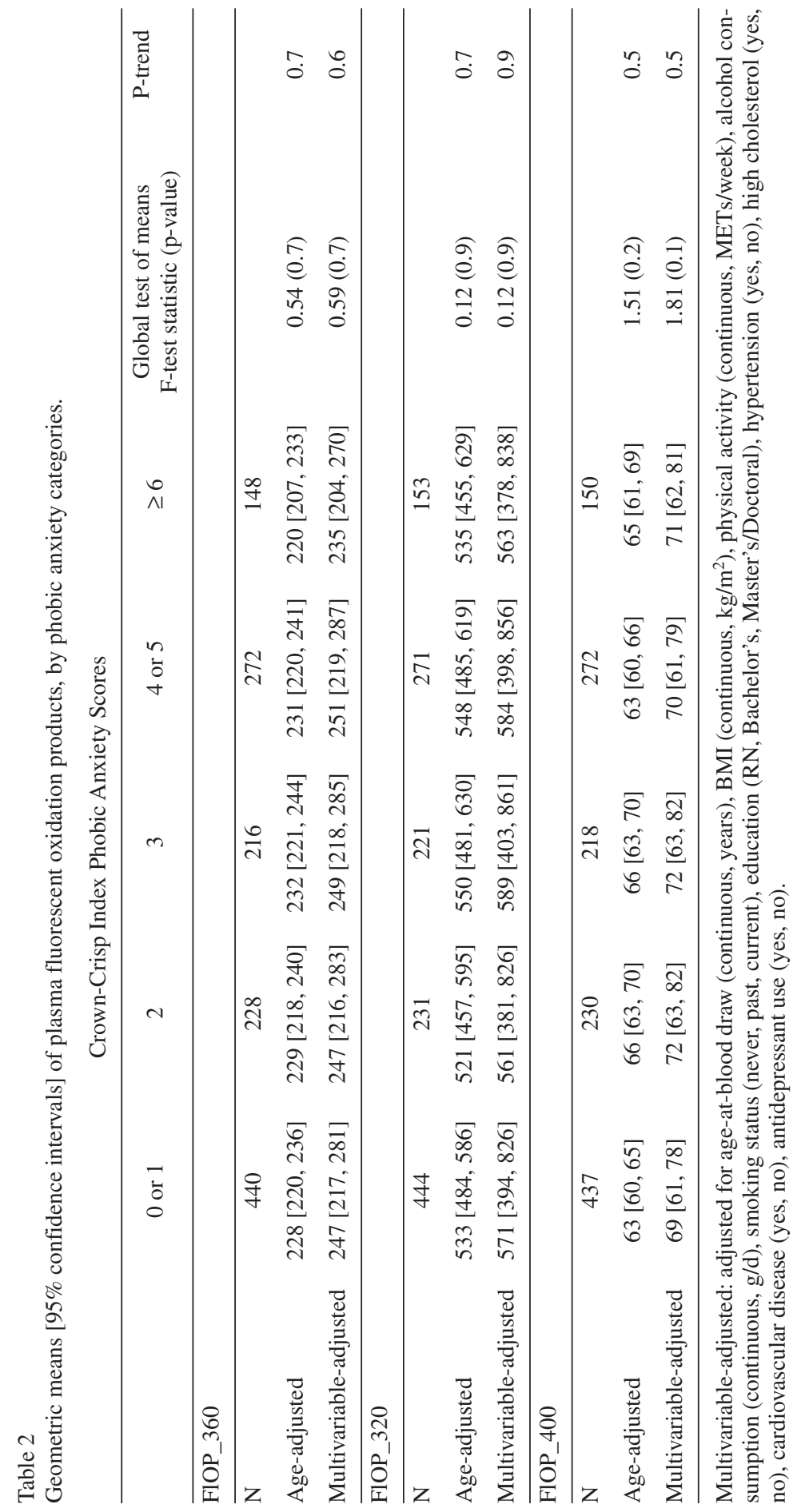


Table 3

Odds ratios [95\% confidence intervals] for high phobic anxiety (Crown-Crisp Score $\geq 6$ ), by quartiles of fluorescent oxidation products.

Quartiles of FlOPs

\begin{tabular}{|c|c|c|c|c|c|}
\hline & Q1 & Q2 & Q3 & Q4 & P-for-linear-trend \\
\hline \multicolumn{6}{|l|}{ FlOP_360 } \\
\hline Cutpoints, FI/mL & $<181$ & 181 to $<220$ & 220 to $<280$ & $\geq 280$ & \\
\hline Age-Adjusted & ref & $0.84[0.53,1.36]$ & $0.84[0.53,1.36]$ & $0.79[0.49,1.28]$ & 0.4 \\
\hline Multivariable-adjusted & ref & $0.81[0.49,1.31]$ & $0.77[0.47,1.28]$ & $0.68[0.40,1.15]$ & 0.2 \\
\hline \multicolumn{6}{|l|}{ FlOP_320 } \\
\hline $\begin{array}{l}\text { Cutpoints, FI/mL } \\
\text {. }\end{array}$ & $<293$ & 293 to $<416$ & 416 to $<629$ & $\geq 629$ & \\
\hline Age-Adjusted & ref & $0.94[0.58,1.52]$ & $0.92[0.57,1.49]$ & $1.06[0.66,1.69]$ & 0.6 \\
\hline Multivariable-adjusted & ref & $0.92[0.56,1.50]$ & $0.88[0.54,1.44]$ & $0.99[0.61,1.61]$ & 0.8 \\
\hline \multicolumn{6}{|l|}{ FlOP_400 } \\
\hline Cutpoints, FI/mL & $<50$ & 50 to $<61$ & 61 to $<80$ & $\geq 629$ & \\
\hline Age-Adjusted & ref & $1.20[0.74,1.94]$ & $1.26[0.78,2.04]$ & $1.00[0.61,1.65]$ & 0.9 \\
\hline Multivariable-adjusted & ref & $1.28[0.78,2.11]$ & $1.23[0.74,2.04]$ & $0.92[0.52,1.63]$ & 0.6 \\
\hline
\end{tabular}

Multivariable-adjusted: adjusted for age-at-blood draw (continuous, years), BMI (continuous, $\mathrm{kg} / \mathrm{m}^{2}$ ), physical activity (continuous, METs/week), alcohol consumption (continuous, g/d), smoking status (never, past, current), education (RN, Bachelor's, Master's/Doctoral), hypertension (yes, no), high cholesterol (yes, no), cardiovascular disease (yes, no), antidepressant use (yes, no).

tion for the differing findings is that, compared to FLOPs, shorter telomeres may be more likely to reflect the cumulative impacts of oxidative stress over long periods of time. Thus, the prior work using the telomere measure may have been less affected by the limitations inherent to using one-time biomarker measures in a cross-sectional design.

This study has a number of strengths including use of a validated anxiety symptom scale, a large well-characterized sample, and adjustment for a large number of potential confounding factors. Potential limitations should also be considered. FlOPs are sensitive yet non-specific markers of global oxidative stress. Thus, we could not address whether a more specific biomarker (e.g., that which measures a single macromolecule type) would have produced similar results. It is possible that phobic anxiety is related to elevations in specific oxidation pathways (e.g. DNA oxidation) but there is no relation to global oxidation levels detected by FlOPs. This offers a potential explanation for the different findings in the current analysis and prior studies that identified significant associations between psychological symptoms and specific markers for lipid or DNA oxidation. Furthermore, FlOPs may reflect other products besides oxidation that may generate fluorescence $^{36}$. The design of this study was cross-sectional and thus cannot inform the evidence base regarding the temporal relationship between phobic anxiety and systemic oxidative stress. Although generalizability is another potential concern (participants were predominantly (95\%) of white and European 
Supplementary Table 1.

Odds ratios [95\% confidence intervals] for polytomous logistic regression models of phobic anxiety, per 1-SD unit in log-FlOPs.

$$
\text { OR per } 1 \mathrm{SD} \log \text {-FlOPs }[95 \% \mathrm{CI}] \quad \text { p-value }
$$

\begin{tabular}{|c|c|c|}
\hline FlOP_360 & & \\
\hline Age-adjusted & & \\
\hline $6+$ vs. 0/1 CCI & $0.90[0.75,1.09]$ & 0.2 \\
\hline $4-5$ vs. $0 / 1 \mathrm{CCI}$ & $1.03[0.89,1.20]$ & 0.7 \\
\hline 3 vs. 0/1 CCI & $1.05[0.89,1.23]$ & 0.6 \\
\hline 2 vs. $0 / 1 \mathrm{CCI}$ & $1.01[0.86,1.19]$ & 0.9 \\
\hline Multivariable-adjus & & \\
\hline 6+ vs. 0/1 CCI & $0.86[0.70,1.05]$ & 0.1 \\
\hline $4-5$ vs. $0 / 1 \mathrm{CCI}$ & $1.05[0.90,1.23]$ & 0.6 \\
\hline 3 vs. $0 / 1 \mathrm{CCI}$ & $1.03[0.87,1.23]$ & 0.7 \\
\hline 2 vs. $0 / 1 \mathrm{CCI}$ & $1.01[0.85,1.20]$ & 0.9 \\
\hline FlOP_320 & & \\
\hline Age-adjusted & & \\
\hline $6+$ vs. $0 / 1 \mathrm{CCI}$ & $1.00[0.84,1.21]$ & 0.9 \\
\hline $4-5$ vs. $0 / 1$ CCI & $1.03[0.89,1.19]$ & 0.7 \\
\hline 3 vs. $0 / 1 \mathrm{CCI}$ & $1.03[0.88,1.21]$ & 0.7 \\
\hline 2 vs. $0 / 1$ CCI & $0.98[0.83,1.15]$ & 0.8 \\
\hline Multivariable-adjus & & \\
\hline $6+$ vs. 0/1 CCI & $0.99[0.82,1.20]$ & 0.9 \\
\hline $4-5$ vs. $0 / 1$ CCI & $1.02[0.88,1.19]$ & 0.8 \\
\hline 3 vs. 0/1 CCI & $1.03[0.88,1.21]$ & 0.7 \\
\hline 2 vs. $0 / 1 \mathrm{CCI}$ & $0.98[0.83,1.16]$ & 0.8 \\
\hline FlOP_400 & & \\
\hline Age-adjusted & & \\
\hline $6+$ vs. $0 / 1$ CCI & $1.10[0.92,1.33]$ & 0.3 \\
\hline $4-5$ vs. $0 / 1$ CCI & $1.02[0.88,1.19]$ & 0.8 \\
\hline 3 vs. 0/1 CCI & $1.16[0.99,1.37]$ & 0.1 \\
\hline 2 vs. $0 / 1 \mathrm{CCI}$ & $1.17[0.99,1.37]$ & 0.1 \\
\hline Multivariable-adjus & & \\
\hline $6+$ vs. 0/1 CCI & $1.09[0.88,1.34]$ & 0.4 \\
\hline $4-5$ vs. $0 / 1$ CCI & $1.05[0.88,1.24]$ & 0.6 \\
\hline 3 vs. $0 / 1 \mathrm{CCI}$ & $1.15[0.96,1.38]$ & 0.1 \\
\hline 2 vs. $0 / 1 \mathrm{CCI}$ & $1.16[0.97,1.39]$ & 0.1 \\
\hline
\end{tabular}

Multivariable-adjusted: adjusted for age-at-blood draw (continuous, years), BMI (continuous, $\mathrm{kg} / \mathrm{m}^{2}$ ), physical activity (continuous, METs/week), alcohol consumption (continuous, g/d), smoking status (never, past, current), education (RN, Bachelor's, Master's/Doctoral), hypertension (yes, no), high cholesterol (yes, no), cardiovascular disease (yes, no), antidepressant use (yes, no). 
race/ethnicity), it is unlikely that this issue had any influence on the null associations in this report; nevertheless, we acknowledge that work in more diverse samples would be required in order to address important questions of whether race/ethnicity variably influences psychological distress-oxidative stress/injury associations. Lastly, although we were able to adjust for numerous covariates, confounding by unmeasured factors is still possible, as may occur in any observational study. However, the relative homogeneity of our cohort reduces potential influences of many important unmeasured confounders, such as those relate to health knowledge or access to care.

In summary, phobic anxiety levels were not associated with plasma fluorescent oxidation products measured at three different wavelengths among participants in this large cross-sectional study. As FlOPs are a nonspecific marker of global oxidative stress, future research on this topic may be enhanced by use of more specific biomarkers, such as DNA-related markers. Additionally, future work would be enriched by use of prospective designs that could inform temporal understanding of either how anxiety may relate to the evolution of oxidative stress/injury measures or how oxidative stress may be associated with the development of anxiety.

\section{Acknowledgements}

This work was supported by National Institutes of Health (NIH) grants P01 CA87969, R01 CA49449, R01 CA131218 and R01 MH096776. Dr. Wu was supported by the American Heart Association grant 0430202N. Dr. Okereke was supported by the Harvard Medical School Eleanor and Miles Shore Fellowship. The funders had no role in the study design, data collection and analysis, decisions to publish, or preparation of the manuscript. The authors thank Dr. Mary Townsend for her assistance with the data preparation and manuscript. We also thank the participants of the Nurses' Health Study for their years of dedication and commitment.

\section{Conflict of interest}

The authors have no conflicts of interest to report.

\section{References}

1. Kessler RC, Berglund P, Demler O, Jin R, Merikangas KR, Walters EE. Lifetime prevalence and age-of-onset distributions of DSM-IV disorders in the National Comorbidity Survey Replication. Arch Gen Psychiatry. 2005; 62(6): 593-602.

2. Bruce SE, Yonkers KA, Otto MW, Eisen JL, Weisberg $\mathrm{RB}$, Pagano M, et al. Influence of psychiatric comorbidity on recovery and recurrence in generalized anxiety disorder, social phobia, and panic disorder: A 12-year prospective study. Am J Psychiatry. 2005; 162(6): 1179-1187.

3. Kawachi I, Colditz GA, Ascherio A, Rimm EB, Giovannucci E, Stampfer MJ, et al. Prospective study of phobic anxiety and risk of coronary heart disease in men. Circulation. 1994; 89(5): 1992-1997.

4. Albert CM, Chae CU, Rexrode KM, Manson JE, Kawachi I. Phobic anxiety and risk of coronary heart disease and sudden cardiac death among women. Circulation. 2005; 111(4): 480-487.

5. Kuloglu M, Atmaca M, Tezcan E, Ustundag B, Bulut S. Antioxidant enzyme and malondialdehyde levels in patients with panic disorder. Neuropsychobiology. 2002; 46(4): 186-189.

6. Kuloglu M, Atmaca M, Tezcan E, Gecici O, Tunckol $\mathrm{H}$, Ustundag B. Antioxidant enzyme activities and malondialdehyde levels in patients with obsessive-compulsive disorder. Neuropsychobiology. 2002; 46(1): 27-32.

7. Bouayed J, Rammal H, Soulimani R. Oxidative stress and anxiety: Relationship and cellular pathways. Oxid Med Cell Longev. 2009; 2(2): 63-67. 
8. Ng F, Berk M, Dean O, Bush AI. Oxidative stress in psychiatric disorders: Evidence base and therapeutic implications. Int J Neuropsychopharmacol. 2008; 11(6): 851-876.

9. Kuloglu M, Ustundag B, Atmaca M, Canatan H, Tezcan AE, Cinkilinc N. Lipid peroxidation and antioxidant enzyme levels in patients with schizophrenia and bipolar disorder. Cell Biochem Funct. 2002; 20(2): 171-175.

10. Epel ES, Blackburn EH, Lin J, Dhabhar FS, Adler NE, Morrow JD, et al. Accelerated telomere shortening in response to life stress. Proc Natl Acad Sci U S A. 2004; 101(49): 17312-17315.

11. Irie M, Miyata M, Kasai H. Depression and possible cancer risk due to oxidative DNA damage. J Psychiatr Res. 2005; 39(6): 553-560.

12. Brennan AM, Fargnoli JL, Williams CJ, Li T, Willett $\mathrm{W}$, Kawachi I, et al. Phobic anxiety is associated with higher serum concentrations of adipokines and cytokines in women with diabetes. Diabetes Care. 2009; 32(5): 926-931.

13. Copeland WE, Shanahan L, Worthman C, Angold A, Costello EJ. Generalized anxiety and C-reactive protein levels: A prospective, longitudinal analysis. Psychol Med. 2012; 42(12): 2641-2650.

14. Vogelzangs N, Beekman AT, de Jonge P, Penninx BW. Anxiety disorders and inflammation in a large adult cohort. Transl Psychiatry. 2013; 3: e249.

15. Miller GE, Chen E, Zhou ES. If it goes up, must it come down? Chronic stress and the hypothalamic-pituitaryadrenocortical axis in humans. Psychol Bull. 2007; 133(1): 25-45.

16. Atmaca M, Kuloglu M, Tezcan E, Ustundag B. Antioxidant enzyme and malondialdehyde levels in patients with social phobia. Psychiatry Res. 2008; 159(1-2): 95-100.

17. Hovatta I, Tennant RS, Helton R, Marr RA, Singer O, Redwine JM, et al. Glyoxalase 1 and glutathione reductase 1 regulate anxiety in mice. Nature. 2005; 438(7068): 662-666.

18. Bouayed J, Rammal H, Younos C, Soulimani R. Positive correlation between peripheral blood granulocyte oxidative status and level of anxiety in mice. Eur J Pharmacol. 2007; 564(1-3): 146-149.

19. Landgraf R, Kessler MS, Bunck M, Murgatroyd C, Spengler D, Zimbelmann M, et al. Candidate genes of anxiety-related behavior in $\mathrm{HAB} / \mathrm{LAB}$ rats and mice: Focus on vasopressin and glyoxalase-I. Neurosci Biobehav Rev. 2007; 31(1): 89-102.

20. Bilici M, Efe H, Koroglu MA, Uydu HA, Bekaroglu M, Deger O. Antioxidative enzyme activities and lipid peroxidation in major depression: Alterations by antidepressant treatments. J Affect Disord. 2001; 64(1): 43-51.
21. Ersan S, Bakir S, Erdal Ersan E, Dogan O. Examination of free radical metabolism and antioxidant defence system elements in patients with obsessive-compulsive disorder. Prog Neuropsychopharmacol Biol Psychiatry. 2006; 30(6): 1039-1042.

22. Tezcan E, Atmaca M, Kuloglu M, Ustundag B. Free radicals in patients with post-traumatic stress disorder. Eur Arch Psychiatry Clin Neurosci. 2003; 253(2): 89-91.

23. Arranz L, Guayerbas N, De la Fuente M. Impairment of several immune functions in anxious women. J Psychosom Res. 2007; 62(1): 1-8.

24. Colditz GA, Martin P, Stampfer MJ, Willett WC, Sampson L, Rosner B, et al. Validation of questionnaire information on risk factors and disease outcomes in a prospective cohort study of women. Am J Epidemiol. 1986; 123(5): 894-900.

25. Colditz GA. The nurses' health study: A cohort of US women followed since 1976. J Am Med Womens Assoc. 1995; 50(2): 40-44.

26. Crown S, Crisp AH. A short clinical diagnostic selfrating scale for psychoneurotic patients. The Middlesex Hospital Questionnaire (M.H.Q.). Br J Psychiatry. 1966; 112(490): 917-923.

27. Burgess PM, Mazzocco L, Campbell IM. Discriminant validity of the Crown-Crisp Experiential Index. Br J Med Psychol. 1987; 60 (Pt 1): 61-69.

28. Hankinson SE, Manson JE, Spiegelman D, Willett WC, Longcope C, Speizer FE. Reproducibility of plasma hormone levels in postmenopausal women over a 2-3-year period. Cancer Epidemiol Biomarkers Prev. 1995; 4(6): 649-654.

29. Hankinson SE, Willett WC, Manson JE, Hunter DJ, Colditz GA, Stampfer MJ, et al. Alcohol, height, and adiposity in relation to estrogen and prolactin levels in postmenopausal women. J Natl Cancer Inst. 1995; 87(17): 1297-1302.

30. Fortner RT, Tworoger SS, Wu T, Eliassen AH. Plasma florescent oxidation products and breast cancer risk: Repeated measures in the Nurses' Health Study. Breast Cancer Res Treat. 2013; 141(2): 307-316.

31. Jensen MK, Wang Y, Rimm EB, Townsend MK, Willett $\mathrm{W}, \mathrm{Wu}$ T. Fluorescent oxidation products and risk of coronary heart disease: A prospective study in women. J Am Heart Assoc. 2013; 2(5): e000195.

32. Okereke OI, Prescott J, Wong JY, Han J, Rexrode $\mathrm{KM}$, De Vivo I. High phobic anxiety is related to lower leukocyte telomere length in women. PLoS One. 2012; 7(7): e40516.

33. Haines A, Cooper J, Meade TW. Psychological characteristics and fatal ischaemic heart disease. Heart. 2001; 85(4):385-389. 
34. McGrath M, Kawachi I, Ascherio A, Colditz GA, Hunter DJ, De Vivo I. Association between catechol-Omethyltransferase and phobic anxiety. Am J Psychiatry. 2004; 161(9): 1703-1705.

35. Streiner EL, Norman GR. Health Measurement Scales: A Practical Guide to their Development and Use. Oxford: Oxford University Press; 1989: 39-52.

36. Frankel EN. Lipid Oxidation. Dundee: The Oily Press; 1998.

37. Wu T, Rifai N, Willett WC, Rimm EB. Plasma fluorescent oxidation products: Independent predictors of coronary heart disease in men. Am J Epidemiol. 2007; 166(5): 544-551.

38. Wu T, Willett WC, Rifai N, Rimm EB. Plasma fluorescent oxidation products as potential markers of oxidative stress for epidemiologic studies. Am J Epidemiol. 2007; 166(5): 552-560.

39. Wu T, Rifai N, Roberts LJ, 2nd, Willett WC, Rimm EB. Stability of measurements of biomarkers of oxidative stress in blood over 36 hours. Cancer Epidemiol Biomarkers Prev. 2004; 13(8): 1399-1402.

40. Frankel EN, Neff WE, Brooks DD, Fujimoto K. Fluorescence formation from the interaction of DNA with lipid oxidation degradation products. Biochim Biophys Acta. 1987; 919(3): 239-244.

41. Fujimoto K, Neff WE, Frankel EN. The reaction of DNA with lipid oxidation products, metals and reducing agents. Biochim Biophys Acta. 1984; 795(1): 100-107.

42. Flynn TP, Allen DW, Johnson GJ, White JG. Oxidant damage of the lipids and proteins of the erythrocyte membranes in unstable hemoglobin disease. Evidence for the role of lipid peroxidation. J Clin Invest. 1983; 71(5): 1215-1223.

43. Rosner B, Cook N, Portman R, Daniels S, Falkner B. Determination of blood pressure percentiles in normalweight children: Some methodological issues. Am J Epidemiol. 2008; 167(6): 653-666.
44. Rosner B. Percentage points for a generalized ESD many-outlier procedure. Technometrics. 1983; 25(2): 165-172.

45. Okereke OI, Grodstein F. Phobic Anxiety and Cognitive Performance Over 4 Years Among CommunityDwelling Older Women in the Nurses' Health Study. Am J Geriatr Psychiatry. 2013.

46. Sarandol A, Sarandol E, Eker SS, Erdinc S, Vatansever E, Kirli S. Major depressive disorder is accompanied with oxidative stress: Short-term antidepressant treatment does not alter oxidative-antioxidative systems. Hum Psychopharmacol. 2007; 22(2): 67-73.

47. Forlenza MJ, Miller GE. Increased serum levels of 8hydroxy-2'-deoxyguanosine in clinical depression. Psychosom Med. 2006; 68(1): 1-7.

48. Andreazza AC, Frey BN, Erdtmann B, Salvador M, Rombaldi F, Santin A, et al. DNA damage in bipolar disorder. Psychiatry Res. 2007; 153(1): 27-32.

49. Irie M, Asami S, Nagata S, Ikeda M, Miyata M, Kasai H. Psychosocial factors as a potential trigger of oxidative DNA damage in human leukocytes. Jpn J Cancer Res. 2001; 92(3): 367-376.

50. Houben JM, Moonen HJ, van Schooten FJ, Hageman GJ. Telomere length assessment: Biomarker of chronic oxidative stress? Free Radic Biol Med. 2008; 44 (3): 235-246.

Corresponding author:

Olivia I. Okereke, MD, SM

Channing Division of Network Medicine

181 Longwood Avenue

Boston

MA 02115

Phone: 617-525-2027

Fax: 617-525-2008

E-mail: ookereke@partners.org 